\title{
Obstacles to health care transformation are numerous
}

Published at www.cmaj.ca on Aug. 23

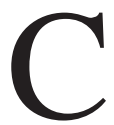

anada's "risk-averse" health care culture may hamper necessary reforms, said experts at the Canadian Medical Association's 143rd annual meeting on Sunday in Niagara Falls, Ontario.

The CMA's proposal to transform the nation's health care system is the focus of this year's meeting. But the changes suggested in its blueprint, Health Care Transformation in Canada: Change that Works, Care that Lasts, could face substantial systemic obstacles to implementation, said Dr. Jack Kitts, president and CEO of the Ottawa Hospital in Ontario. "I think we would all agree that within the current system the patient isn't the centre of the universe for all stakeholders. ... There's turf protection issues and powerful groups with vested interests at all levels, in some cases very strong unions, that resist change."

Disagreement among health care professionals is just one facet of Canada's "culture" of resistance to health care change, and it's letting government off the reform hook, he said. "I think government thrives on the fact we can't get consensus."

Given the "iconic" status of health care in Canada, "there's no great political incentive to stand up and say the system needs to be fundamentally transformed," said Alex Himelfarb, former clerk of the Privy Council of Canada and director of the Glendon School of Public and International Affairs at York University in Toronto, Ontario. "Very few politicians want to lead a reform agenda because, for the most part, we're hanging onto a system that hasn't existed for 10 years."

According to Himelfarb, balancing the national budget in 1995 had the "unanticipated consequence" of putting health care reform on the backburner. "Because of significant cuts to resources, the health care sys-

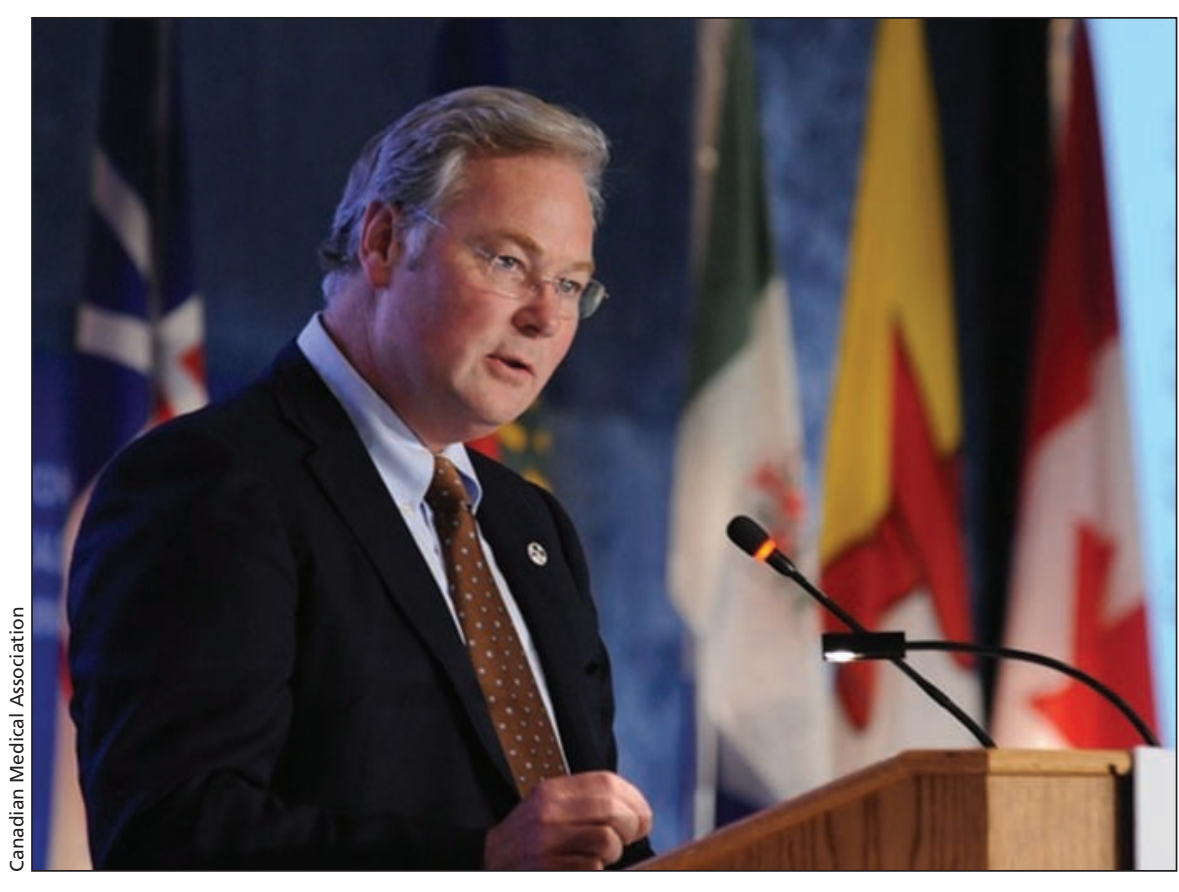

Resistance to change is part of the culture of Canada's health care system, says Dr. Jack Kitts, president and CEO of the Ottawa Hospital in Ontario.

tem has been more focused on surviving than on finding the additional energy to look at where changes are necessary."

In a resource-constrained environment, collaboration has been difficult to foster, said Kitts. "We're not wired to work in teams. The ultimate accountability comes down to the physician-topatient relationship. The physician makes the diagnosis, decides the treatment plan, makes the decisions relating to care, and is ultimately responsible for that care."

Even supposedly universal values of accountability and sustainability mean different things to different people, he said. "Accountability is a word that's been thrown around for years, and used quite loosely by governments and physician groups. What it really requires is setting realistic targets and having the authority to do what it takes to meet those targets, but accountability initiatives that meet those requirements are actually very few. People confuse accountability agreements with service agreements, when they mean totally different things."

"The federal government might see sustainability as containing the cost of transfers for health, while the provinces are dealing with the health care budget pushing out other expenditures, like education, so they want to squeeze the costs," added Himelfarb. "On the other hand, patients see sustainability as a question of 'Can I count on the system to give me quality of care and reasonably timely access without charging me.' And for practitioners, sustainability means getting the tools and resources to provide the quality of care they joined the profession to deliver. How do you reconcile all of that?"

However, opposition to change has been shrinking in recent years, as questions about who will pay for a rapidly aging population have brought new urgency to the reform debate. 
"If we don't start transforming the system now, it will be eroded and then break, and it's too important for Canada's future, for our sense of who we are, for our economic and physical well-being, to allow that to happen," said Himelfarb.

If health care professionals want to see change, they need to form a con- sensus and start demonstrating to government that the tax dollars meted out to health care are already making a difference.

"The more we can do to show that in outcomes and other tangible measures, the more we're in a position to demand more of both the federal and provincial governments," Himelfarb said. "We have to devise sustainability as universal access to quality care that is timely at the lowest possible cost. That needs to be our definition of value for money, and that needs to be agreed upon now." - Lauren Vogel, CMAJ

DOI:10.1503/cmaj.109-3345 